\title{
On the Role of Radicals in Kinetics of Plasma Etchers in $\mathrm{Ar} / \mathrm{CF}_{4}$ Mixtures
}

\author{
Ž. Nikitović* ${ }^{*}$ V. Stojanović and Z.Lu. Petrović \\ Institute of Physics, Pregrevica 118, 11080 Belgrade, Serbia
}

\begin{abstract}
In this paper we present the transport coefficients in $\mathrm{Ar} / \mathrm{CF}_{4}$ mixtures with realistic abundances of $\mathrm{CF}_{x}$ radicals, $\mathrm{F}$ atoms, and $\mathrm{F}_{2}$ molecules that are standard products of plasma chemistry in plasma etching systems and are present in large abundances of the order of few percent in realistic plasma etching devices. It was found that, although radicals make a minimum impact on distribution function and mean energy, the effect on drift velocity is significant and the effect on rates of attachment is large and may change the mode of operation of plasmas.
\end{abstract}

PACS numbers: 51.10.+y, 51.50.+v, 52.25.Fi, 82.20.Pm

\section{Introduction}

In order to achieve high resolution plasma processing for future generations of integrated circuits, the empirical development of the plasma processing tools has to be replaced by a real understanding of the physics and chemistry of plasmas. For that purpose comprehensive realistic geometry codes have been developed. Their aim is to facilitate the development of new devices and to provide real time control of the process. Description of electron kinetics in non-equilibrium plasma modeling necessarily includes calculation of transport coefficients which is based on compilation of cross-sections from different sources. So far only kinetics for the electron-parent gas collisions has been included. Requirement to establish reliable transport coefficients for $\mathrm{Ar} / \mathrm{CF}_{4}$ plasmas is especially important as the practical conditions include many reactive species. In this paper we show transport data for electrons in mixtures of $\mathrm{Ar}$ and $\mathrm{CF}_{4}$ and with abundances of radicals that are close to those found in practical processing devices.

Carbon tetrafluoride is one of the most often used gases in today's semiconductor industry. It is primarily applied for etching of substrates of different materials where the most important is $\mathrm{SiO}_{2}$. It is also used for the formation of fluorinated polymer films where production is correlated to high concentrations of $\mathrm{CF}$ and $\mathrm{CF}_{2}$ radicals [1].

$\mathrm{CF}_{4}$ has also an important role in technological applications such as development of gaseous circuit breakers [2] and for development of particle detectors [3-5]. $\mathrm{CF}_{4}$ belongs to freons that unfortunately significantly affect global warming of our planet. Its atmospheric half-time is estimated to reach over 50000 years and it has a large potential to contribute global warming. Because of that

\footnotetext{
* corresponding author; e-mail: zeljka@phy.bg.ac.yu
}

it is important to continue research related to removal of this freon from the atmosphere by applying gas discharges (e.g. by focused microwave radiation [6]).

$\mathrm{CF}_{4}$ has an advantage with respect to other gases primarily due to the low level of toxicity and relatively low cost. At room temperature it has low reactivity in its electronic ground state. Because no stable excited states exist it dissociates in plasma treatments where it becomes a source of reactive particles (ions, neutrals, radicals).

In capacitively coupled plasma (CCP) [7] and inductively coupled plasma (ICP) [8] etching reactors the dominant reactive radical is $\mathrm{CF}_{2}$. Recent advances in measurements and calculations of electron scattering cross-sections [9] on $\mathrm{CF}_{4}$ radicals in the energy domain relevant to non-equilibrium plasmas have shown that probabilities for many processes involving those radicals are significantly larger than for $\mathrm{CF}_{4}$ itself. It is even likely that $\mathrm{CF}_{2}$ radical may reclaim a dominant role for certain processes in plasma. It is now possible to build a more precise quantitative picture about rate coefficients in realistic gas mixtures and improve control of radical concentration in order to optimize these processes.

Pure $\mathrm{CF}_{4}$ plasmas are rarely used in material processing and instead are diluted with $\mathrm{Ar}$ and $\mathrm{O}_{2}$ to control the production of fluorocarbons and provide selectivity in etching. In this work we calculated electron transport coefficients for mixtures of $\mathrm{Ar} / \mathrm{CF}_{4}$ in order to estimate radical concentrations at which dominant radical influence is achieved in collisions of electrons with $\mathrm{CF}_{4}$. In Ar the mean energies are likely to be larger for the same effective field and thus the overall kinetics may be quite different as compared to pure $\mathrm{CF}_{4}$.

\section{Monte Carlo code and two term approximation}

Electron kinetics in pure $\mathrm{CF}_{4}$ is well described by the set of cross-sections of Kurihara et al. [10] which is our 
starting point. Requirement to establish reliable transport coefficients for $\mathrm{CF}_{4}$ plasmas is especially demanding for conditions that include many reactive species.

Free radical species, such as $\mathrm{CF}_{y}(y=1-3)$ and fluorine atoms, play important but complex roles in plasma processing. We calculated electron transport coefficients for binary mixture of $90 \% \mathrm{Ar}$ and $\mathrm{CF}_{4}$. In order to determine the role of radicals, we added up $1 \%$ of radical $\mathrm{X}$ species $\left(\mathrm{X}=\mathrm{F}, \mathrm{F}_{2}, \mathrm{CF}, \mathrm{CF}_{2}\right.$ and $\left.\mathrm{CF}_{3}\right)$ replacing the equivalent amount of $\mathrm{CF}_{4}$. Calculations were made for conditions overlapping with those found in plasma technologies for semiconductor device manufacturing. Set of cross-sections for $\mathrm{CF}, \mathrm{CF}_{2}$ and $\mathrm{CF}_{3}$ is based on the work of Rozum et al. [9]. Set of cross-sections for $\mathrm{F}_{2}$ is from [11], $\mathrm{F}$ is according to Gudmundsson [12] and for Ar to Hayashi [13].

We calculated attachment and ionization rate coefficients for $1 \%$ of the radical species $\mathrm{X}$ in $\mathrm{Ar} / \mathrm{CF}_{4}$. Transport coefficients are obtained by using a two term approximation to the electron Boltzmann equation [14] and by Monte Carlo simulations [15].

\section{Results and discussion}

The basic cross-sections of pure $\mathrm{CF}_{4}$ were used from [10] with a modification made in [16] in order to include production of $\mathrm{CF}_{3}^{-}$ions. Complete cross-section set is shown in Fig. 1.

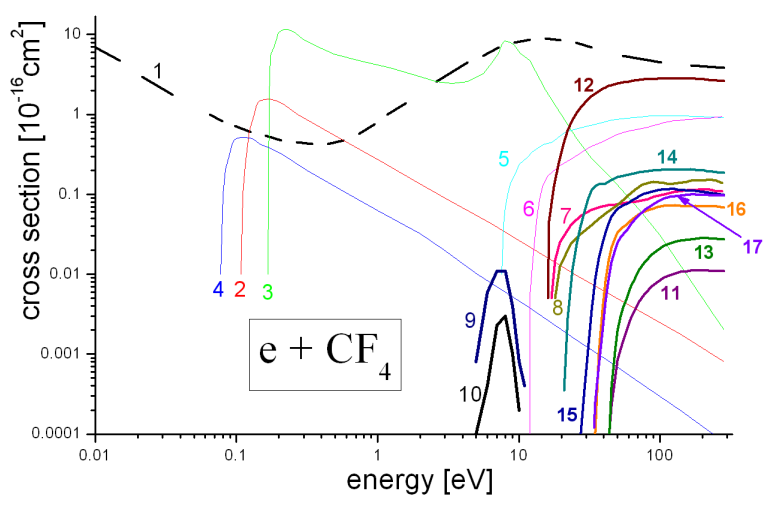

Fig. 1. Electron impact cross-sections for scattering on $\mathrm{CF}_{4} 1$ - electronic momentum transfer, 2 - vibronic excitation $v=1,3$ - vibronic excitation $v=3,4-$ excitation $v=4,5$ - electronic excitation, 6 - dissociation to products $\mathrm{CF}_{3}, 7$ - dissociation to products $\mathrm{CF}_{2}, 8$ - dissociation to products $\mathrm{CF}, 9$ - dissociative attachment $\left(\mathrm{F}^{-}\right), 10$ - dissociative attachment $\left(\mathrm{CF}_{3}^{-}\right)$, 11 - ionization $\mathrm{CF}_{3}^{+}+\mathrm{F}+2 \mathrm{e}, 12-\mathrm{CF}_{3}^{+}+\mathrm{F}+2 \mathrm{e}, 13-$ $\mathrm{CF}_{3}^{2+}+\mathrm{F}+3 \mathrm{e}, 14-\mathrm{CF}_{2}^{+}+2 \mathrm{~F}+2 \mathrm{e}, 15-\mathrm{CF}^{+}+3 \mathrm{~F}+2 \mathrm{e}$, $16-\mathrm{C}^{+}+4 \mathrm{~F}+2 \mathrm{e}, 17-F^{+}+C F_{3}+2 e$.

Electron mean energy and electron drift velocity in mixtures $\mathrm{Ar} / \mathrm{CF}_{4}$ as a function of $E / N$ are shown in Fig. 2. From our earlier studies [10] we could estimate that the difference between Monte Carlo and Boltzmann equation solution results is significant above $10 \mathrm{Td}$ $\left(1 \mathrm{Td}=10^{21} \mathrm{Vm}^{2}\right)$ and is not greater than few percent for characteristic energy and is even smaller for drift velocities. Monte Carlo results are not own here as the extent of the inaccuracy of the two term approximation is not affected by the presence of radicals and also as calculations of processes with radicals that have small abundances may require exceedingly long computing times for some processes to reach good statistics.

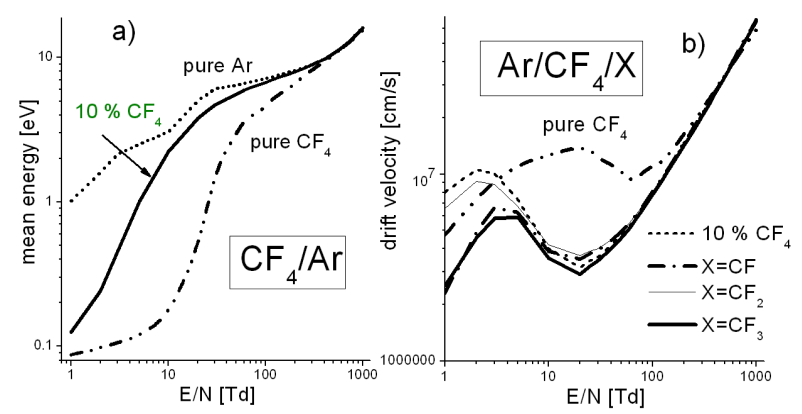

Fig. 2. (a) Mean energy and (b) drift velocity as a function of $E / N$ for $\mathrm{Ar} / \mathrm{CF}_{4}$ mixture. Drift velocity for $90 \% \mathrm{Ar}, 9 \% \mathrm{CF}_{4}$ and $1 \%$ radicals $\mathrm{X}$ in the mixture. We also show results for the pure $\mathrm{CF}_{4}$.

Effect of radicals in $\mathrm{Ar} / \mathrm{CF}_{4}$ mixture is observed by forming ternary mixture consisting of $90 \% \mathrm{Ar}$ and $1 \%$ abundance of radicals. Effect of radicals on drift velocity is significant only below $5 \mathrm{Td}$ where $\mathrm{CF}_{3}$ and $\mathrm{CF}$ radicals play a dominant role. Rate coefficient in the mixture is affected both by the changes of the electron energy distribution function (EEDF) and the shape of the cross-section.

Rate coefficients for formation of $\mathrm{F}^{-}, \mathrm{CF}_{3}^{-}$and $\mathrm{CF}_{3}^{+}$ ions calculated for the $\mathrm{Ar} / \mathrm{CF}_{4}$ mixture are presented in Fig. 3a. In principle, almost negligible differences between low and higher abundance data indicate very small perturbations of the EEDF as those ions are produced in collisions of electrons with $\mathrm{CF}_{4}$ molecules.
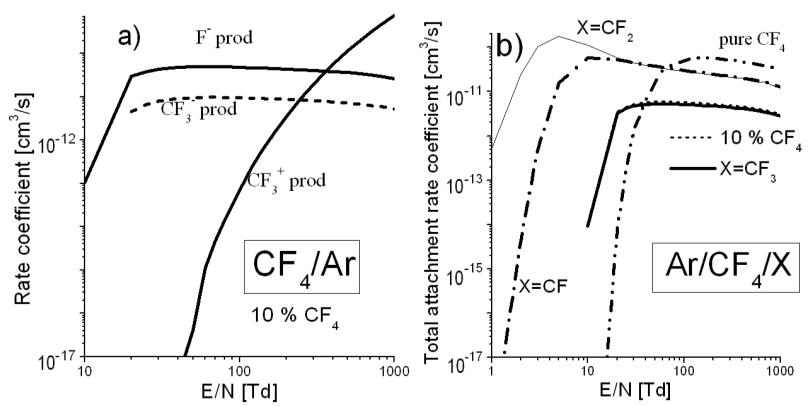

Fig. 3. (a) Rate coefficients for positive and negative ion production and (b) total rate coefficients for attachment in $\mathrm{Ar} / \mathrm{CF}_{4}$ mixture.

Total rate coefficient for electron attachment is obtained as a sum of electron attachment contributions due to $\mathrm{CF}_{4}$ and due to the selected radical for the assumed 
abundance $A$ :

$$
\eta_{\text {tot }}=(0.1-A)\left(\eta_{\mathrm{CF}_{3}^{-} \operatorname{prod}}+\eta_{\mathrm{F}^{-} \operatorname{prod}}\right)+A \eta_{\mathrm{X}}
$$

where $\eta_{\mathrm{X}}$ is attachment rate coefficient for constituent $\mathrm{X}$ of the mixture.

In Fig. 3a total attachment rate coefficient for pure $\mathrm{CF}_{4}$ is compared to the values obtained with $90 \%$ of $\mathrm{Ar}$ plus $1 \%$ of radicals. Significant changes are observed for the ternary mixtures with $\mathrm{CF}$ or $\mathrm{CF}_{2}$ radicals while a decrease in the total attachment for binary mixtures is due to the reduction of $\mathrm{CF}_{4}$ concentration.

\section{Conclusion}

It was shown in this paper that even at small abundances some rate and transport coefficients may change drastically and the best example is the attachment rate. The most abundant radical in plasmas containing $\mathrm{CF}_{4}$ is $\mathrm{CF}_{2}$ [17] and it can be found even at abundances of the order of several \%. As $\mathrm{CF}$ and $\mathrm{CF}_{2}$ have attachment at low energies with thresholds considerably smaller than that of the dissociative electron attachment for electrons in $\mathrm{CF}_{4}$ the overall attachment rate is enhanced and extended to lower energies. Attachment rate at low mean energies increases many orders of magnitude, even the peak value is increased considerably.

Adding $\mathrm{Ar}$ in $\mathrm{CF}_{4}$ mixture has effect on the increase in the mean energy while addition of radicals decreases the mean energy mainly at low $E / N$ values. The effect on other transport coefficients is small except at low $E / N$. Relatively strong influence of radicals on the drift velocity or to be more precise on the negative differential conductivity (NDC) effect is observed only at $E / N$ below about $5 \mathrm{Td}$. It is mainly due to filling of the RamsauerTownsend minimum of both $\mathrm{Ar}$ and $\mathrm{CF}_{4}$ by a relatively high momentum transfer cross-section of the radicals.

The presence of radicals has only a considerable effect on the attachment rates especially at low mean energies. As the distribution functions suffer only a minor change due to the presence of the radicals we may conclude that the observed change of the attachment rate is predominately due to introduction of the low energy attachment to the radicals.

As discussed above, the effect of radicals on transport coefficients may be important in understanding possible discrepancies between experiments and models that do not include the cross-sections for electron collisions with radicals. It is also of importance for understanding electronegative plasmas and for reducing charging damage by using double layers to accelerate negative ions into the charged high aspect ratio structures in dielectrics [18].

\section{Acknowledgments}

The authors acknowledge financial support of the Ministry of Science of the Republic of Serbia (grant No. OI141025).

\section{References}

[1] J.P. Booth, H. Abada, P. Chabert, D.B. Graves, in: Proc. 22nd Summer School and Int. Symp. on the Physics of Ionized Gases, Eds. Lj. Hadžijevski, T. Grozdanov, N. Bibić,Tara, Bajina Bašta (Serbia) 2004, p. 252.

[2] S.R. Hunter, J.G. Carter, L.G. Christophorou, J. Appl. Phys. 58, 3001 (1985).

[3] D.R. James, L.G. Christophorou, R.A. Mathis, in: Gaseous Dielectrics II, Ed. L.G. Christophorou, Pergamon, New York 1980, p. 115.

[4] M.K. Kopp, K.H. Valentine, L.G. Christophorou, J.G. Carter, Nucl. Instrum. Methods 201, 395 (1982).

[5] T. Yamashita, H. Kurashige, M.M. Morii, T.T. Nakamura, T. Nomura, N. Sasao, K. Shibata, Y. Fukushima, Y. Ikegami, H. Kobayashi, T. Taniguchi, Nucl. Instrum. Methods Phys. Res. A 317, 213 (1992).

[6] S. Bzenić, S.S. Manola, Z.Lj. Petrović, in: Proc. 25th European Microwave Conf., Ed. V. Rizzoli, Swanley Nexus, Bologna 1995, p. 856.

[7] T. Nakano, S. Samukawa, J. Vac. Sci. Technol. A 17, 686 (1999).

[8] K. Hioki, K. Hirata, N. Nakano, Z.Lj. Petrović, T. Makabe, J. Vac. Sci. Technol. A 18, 864 (2000).

[9] I. Rozum, P. Limao-Vieira, S. Eden, J. Tennyson, N.J. Mason, J. Phys. Chem. Ref. Data 35, 267 (2006).

[10] M. Kurihara, Z.Lj. Petrović, T. Makabe, J. Phys. D, Appl. Phys. 33, 2146 (2000).

[11] W.L. Morgan, Plasma Chemistry and Plasma Processing 12, 449 (1992).

[12] J.T. Gudmundsson, J. Phys. D, Appl. Phys. 35, 328 (2002).

[13] M. Hayashi, private communication, 1992.

[14] W.L. Morgan, B.M. Penetrante, Comp. Phys. Commun. 58, 127 (1990).

[15] Z.Lj. Petrović, V.D. Stojanović, J. Vac. Sci. Technol. A 16, 329 (1998).

[16] Z. Donko, private communication, 2006.

[17] Ž. Nikitović, V. Stojanović, Z.Lj. Petrović, to be published in Plasma Sources Sci. Technol.

[18] T. Ohmori, T.K. Goto, T. Kitajima, T. Makabe, Appl. Phys. Lett. 83, 4637 (2003). 